\title{
Right atrial mass diagnosed during endoscopic ultrasound in a patient with intraductal papillary mucinous neoplasm of the pancreas and dyspnea
}

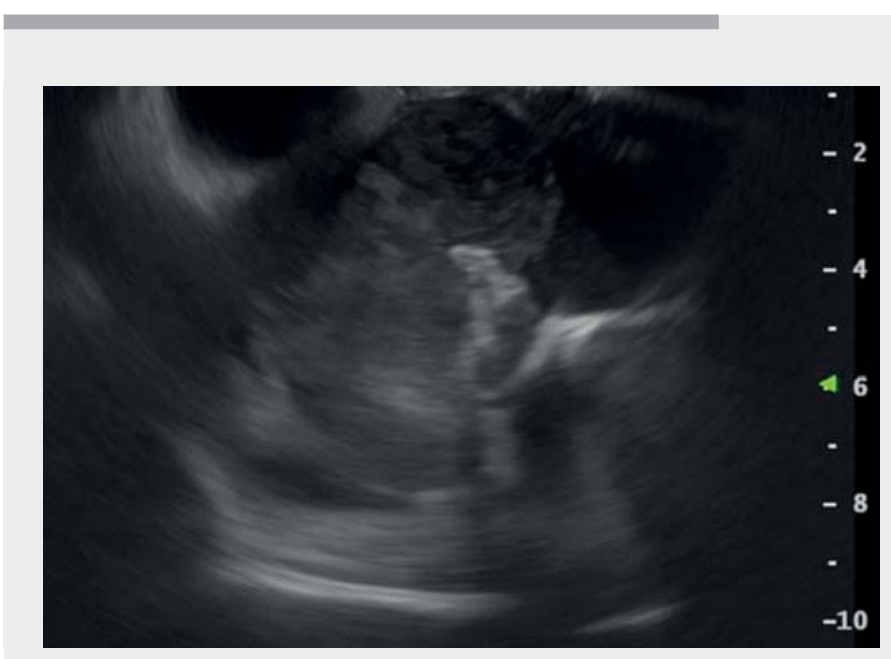

Video 1 Accidental diagnosis of a right atrial mass during endoscopic ultrasound in a patient with intraductal papillary mucinous neoplasm of the pancreas and dyspnea.

A 70-year-old woman with a 10-year history of a $30-\mathrm{mm}$ pancreatic cyst was referred to our center to continue followup. Of note, before the procedure she reported worsening dyspnea and fatigue over the last 4 months. However, no significant alterations were found on either preliminary cardiological or pneumological evaluation. Endoscopic ultrasound (EUS) confirmed the multilocular cystic lesion in the pancreatic body originating from the branch ducts, with focally thickened enhanced walls and a dilation of the main pancreatic duct $(6 \mathrm{~mm})$, as per a mixed-type intraductal papillary mucinous neoplasm (IPMN) with worrisome features. While withdrawing the echoendoscope into the mediastinum, a mainly hyperechoic $70 \times 50-\mathrm{mm}$ inhomogeneous mass was detected in the right atrium ( $\triangleright$ Video 1 ), with an extension towards the superior vena cava access ( Fig.1). Owing to the suspicion of a cardiac mass, multimodality cardiac imaging was performed, confirming an endoluminal right atrial mass ( $>$ Fig.2), with inhomogeneous contrast enhancement, partially engaging the atrial outlet of the superior vena cava ( $>$ Fig. 3 ). Thus, the patient underwent surgical resection of the mass.

Final diagnosis on the surgical specimen revealed an atrial myxoma. Atrial myxomas are rare tumors that may cause fatigue, syncope, shortness of breath, orthopnea, or pulmonary edema [1]. A few cases of left atrial myxoma have already been described that were found incidentally during EUS [2,3]. Interestingly, in this case the right atrium was visible due to the presence of the mass and its extension towards the superior vena cava. It is known that the more you look, the more you see, and EUS is a powerful tool for looking at the anatomical structures and abnormalities around the gastrointestinal tract. In this case, the dyspnea prompted our curiosity to

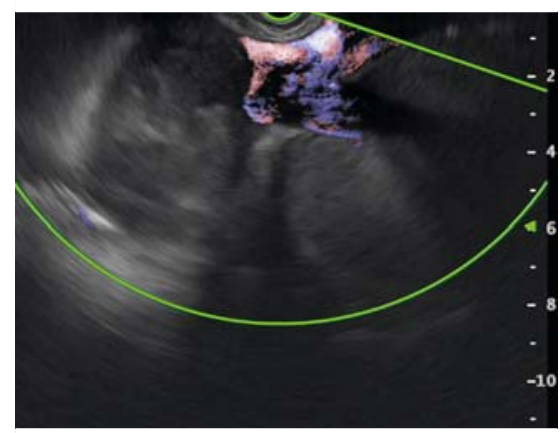

-Fig. 1 Right atrial mass with extension towards the superior vena cava access.

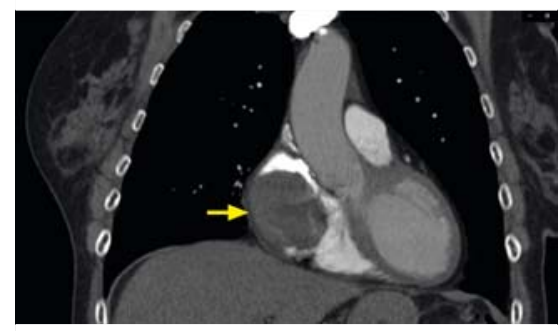

Fig. 2 Computed tomography scan of the right atrial mass.

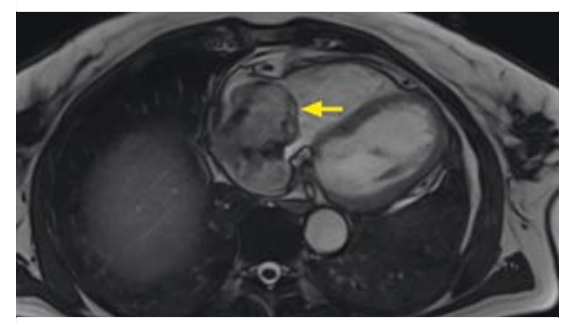

- Fig. 3 Magnetic resonance imaging of the right atrial mass.

examine the cardiac morphology before turning on the light in the endoscopic room.

Endoscopy_UCTN_Code_CCL_1AF_2AC 


\section{Competing interests}

The authors declare that they have no conflict of interest.

The authors

Silvia Carrara ${ }^{1}$, Marco Spadaccini ${ }^{1,2}$, Matteo Colombo $^{1,2}$, Vittorio Pedicini ${ }^{3}$, Lucia Torracca $^{4}$, Alessandro Repici ${ }^{1,2}$

1 IRCCS Humanitas Research Hospital, Endoscopic Unit, Department of Gastroenterology, Milan, Italy

2 Department of Biomedical Sciences, Humanitas University, Milan, Italy

3 IRCCS Humanitas Research Hospital, Unit of Interventional Radiology, Milan, Italy

4 IRCCS Humanitas Research Hospital, Cardiac Surgery Division, Department of Cardiovascular Medicine (A.F.L.T.), Milan, Italy

\section{Silvia Carrara, MD}

IRCCS Humanitas Research Hospital,

Endoscopic Unit, Department of

Gastroenterology, Via Manzoni 56, 20089 Rozzano, Milan, Italy

silvia.carrara@humanitas.it

\section{References}

[1] Kakouros N, McWilliams E, Giles ]. Left atrial myxoma. J Cardiovasc Comput Tomogr 2008; 2: 188-90

[2] Kaura T, Latif SU. Left atrial myxoma diagnosed by EUS examination. Gastrointest Endosc 2020; 91: 712-713

[3] Fazendas P, Marques PP, Tortosa F et al. Cardiac incidentaloma during endoscopic ultrasound: cardiac myxoma with GamnaGandy bodies. Endoscopy 2014; 46: E122E123
Bibliography

Endoscopy 2022; 54: E492-E493

DOI 10.1055/a-1638-9369

ISSN 0013-726X

published online 8.10.2021

(c) 2021. Thieme. All rights reserved.

Georg Thieme Verlag KG, Rüdigerstraße 14,

70469 Stuttgart, Germany

\section{ENDOSCOPY E-VIDEOS}

https://eref.thieme.de/e-videos

口回 Endoscopy E-Videos is an open access online section, 回: reporting on interesting cases and new techniques in gastroenterological endoscopy. All papers include a high quality video and all contributions are freely accessible online. Processing charges apply (currently EUR 375), discounts and wavers acc. to HINARI are available.

This section has its own submission website at https://mc.manuscriptcentral.com/e-videos 